\title{
QUEEN'S
UNIVERSITY
BELFAST
}

\section{Simple high sensitivity wireless transceiver}

Buchanan, N. B., \& Fusco, V. (2014). Simple high sensitivity wireless transceiver. Microwave and Optical Technology Letters, 56(4), 790-792. https://doi.org/10.1002/mop.28205

\author{
Published in: \\ Microwave and Optical Technology Letters
}

Document Version:

Peer reviewed version

Queen's University Belfast - Research Portal:

Link to publication record in Queen's University Belfast Research Portal

\section{Publisher rights}

Copyright @ 2014 Wiley Periodicals, Inc.

This is the peer reviewed version of the following article: Buchanan, NB \& Fusco, V 2014, 'Simple high sensitivity wireless transceiver' Microwave and Optical Technology Letters, vol 56, no. 4, pp. 790-792, which has been published in final form at

http://onlinelibrary. wiley.com/doi/10.1002/mop.28205/abstract. This article may be used for non-commercial purposes in accordance with Wiley Terms and Conditions for Self-Archiving.

\section{General rights}

Copyright for the publications made accessible via the Queen's University Belfast Research Portal is retained by the author(s) and / or other copyright owners and it is a condition of accessing these publications that users recognise and abide by the legal requirements associated with these rights.

\section{Take down policy}

The Research Portal is Queen's institutional repository that provides access to Queen's research output. Every effort has been made to ensure that content in the Research Portal does not infringe any person's rights, or applicable UK laws. If you discover content in the Research Portal that you believe breaches copyright or violates any law, please contact openaccess@qub.ac.uk. 


\title{
Simple high sensitivity wireless transceiver
}

\author{
N.B. Buchanan ${ }^{1}$, V. Fusco ${ }^{2}$
}

The Institute of Electronics, Communications and Information Technology (ECIT), Queen's University Belfast, Northern Ireland Science Park, Queen's Road, Queen's Island, Belfast, United Kingdom BT3 9DT

${ }^{1} \mathrm{n}$. buchanan@ecit.qub.ac.uk

${ }^{2}$ v.fusco@ecit.qub.ac.uk

\begin{abstract}
This paper describes an extremely simple wireless transceiver, comprising of only a low Q VCO and a phase locked loop IC. It is experimentally shown to simultaneously transmit an $8 \mathrm{dBm} \mathrm{CW}$ interrogation signal while concurrently demodulating a phase modulated received signal with sensitivity levels of $-120 \mathrm{dBm}$. This makes the performance similar to conventional transceivers which require complex superheterodyne type architectures and also require a means to provide a high isolation separate the transmit/receive signals (such as a circulator).
\end{abstract}

Index Terms - Phase Locked Loop, Injection Locked Oscillator, Radio Receiver.

\section{Introduction}

In this paper we present an extremely simple wireless transceiver comprising of a low Q VCO and a phase locked loop IC. No other components are necessary. As well as the obvious benefit of simplification, one of the major advantages of this new architecture is that it does not require any isolation between transmit and receive paths, since the VCO carries out both transmit and receive functions simultaneously. The system is most effective when the receive frequency is very close to the transmit frequency. To the authors knowledge, this is the first time that the simplified 
arrangement, reported in this paper, has been used to detect phase modulated signals, similar arrangements, e.g. [3], have only previously demonstrated demodulation of pulse modulated signals.

In this paper we will discuss the simplified transceiver within the context of a backscatter RFID application, where the received frequency is almost equal to the transmit frequency.

A typical RFID interrogator [1], shown in Fig. 1(a) uses modulated backscatter, which provides unique modulation on the return path signal. If this is detected using a conventional transmitter/receiver arrangement as in Fig. 1(a), then the received signal is limited by the isolation between transmit/receive signal paths. This isolation is difficult to achieve in practice and is often achieved using circulators or separate TX/RX antennas, neither of which provide a simple and effective solution. Our new approach, Fig. 1(b) uses a single VCO which acts both as transmitter and highly sensitive receiver, completely removing any requirements for TX/RX isolation. The system can efficiently detect pulse modulated signals and, unlike most simple detectors, is also equally as efficient at detecting phase modulated signals. Phase modulation is easy to implement on RFID tags by simple load-dependent scattering modulators [2] and has the advantage of allowing reasonable bit error rates for lower signal to noise ratios than pulse modulated signals. This increases the range of RFID systems without adding complexity.

\section{Detector Theory of Operation}

In order to describe the theory of operation, we refer to the theory of injection locked oscillators reported in $[4,5]$. Consider the case of an oscillator being injection locked by a signal tending to the same frequency as the oscillators free running 
frequency $\left(\omega_{0}\right)$. In this case the frequency difference of the two signals, $\Delta \omega$, tends to zero. Assuming all other conditions are unchanged then, according to Equation (1), [2], as $\Delta \omega \rightarrow 0$, then $\mathrm{P}_{\mathrm{i}} \rightarrow 0$ and high sensitivity reception can occur. In reality it would also be expected that effects of thermal noise will provide some limitation on the lowest value of locking power obtained.

$$
\Delta \omega=\frac{\omega_{o}}{Q_{e x t}} \sqrt{\frac{P_{i}}{P_{o}}} \frac{1}{\cos \theta}
$$

\section{Characterisation}

To allow characterisation of the receiver's performance with regard to injection locking, [4], it is first necessary to obtain the Q factor ( $Q_{e x t}$, Equation 1) for the free running VCO, (in this case a Mini Circuits POS1025 VCO). Using the setup of Fig. 2 a signal generator was used to inject a signal into the $20 \mathrm{~dB}$ coupler. Locking bandwidths obtained over different injection locking powers $\left(P_{i}\right)$ applied to Equation 1 show that the average $Q_{e x t}$ of the VCO is 75 . The VCO chosen for this application should be un-buffered, as any buffer stage between the VCO and output greatly reduces its injection locking sensitivity. This is an added advantage, as it simplifies the VCO component count, since it can be produced using as little as a single active oscillating device, a low Q passive resonant circuit, and a frequency tuning device, such as a varactor.

To allow detection of phase modulated signals the VCO must be operating within its injection locked region. The frequency offset from the injected signal $(\Delta \omega)$, compared to the oscillator free running signal to achieve the injection locked condition is shown in Fig. 3. This was calculated by substituting the value of the VCO 
Q factor ( $\left.Q_{e x t}\right)$ of 75 and the VCO output power (measured at $6.3 \mathrm{~mW}$ ) into Equation (1), to obtain the value of $\Delta \omega$. It can then be assumed that any condition under the curve of Fig. 3 is injection locked. It can be clearly seen, taking -70dBm input power as an example, that the region where $\Delta \omega<1.5 \mathrm{KHz}$ and $P_{i}>-70 \mathrm{dBm}$ is completely enclosed under the curve (shaded region, Fig. 3), and therefore is injection locked. Therefore any signal at $-70 \mathrm{dBm}$ more than $1.5 \mathrm{KHz}$ away from the oscillator free running frequency should not be detected. This provides an added advantage of high selectivity without complicated filtering

Since the system reported here operates in the injection locked region, it is different to other reported homodyne self oscillating detectors e.g. [3], which are not injection locked by the received signal since they operate at values of $\Delta \omega$ which place them above the curve of Fig. 3, i.e. they behave as a self oscillating mixer, not an injection locked detector, and consequently this makes them sensitive only to amplitude modulated signals. The system reported here, which is injection locked, also has the capability to detect both amplitude as well as phase modulation (PSK).

\section{Experimental Results}

Using the experimental setup of Fig. 2, with 600bps QPSK backscatter modulation, a demodulated signal is produced of $-57 \mathrm{dBV} @$ Pin=-30dBm and $-135 \mathrm{dBV}$ @ Pin $=-120 \mathrm{dBm}$, Fig.4 . The response is linear up to $-30 \mathrm{dBm}$ giving a dynamic range of $90 \mathrm{~dB}$ suggesting that AGC circuits should not be required. Assuming a received power level of $-120 \mathrm{dBm}$, a $10 \mathrm{~dB}$ gain in the TX/RX and the backscatter tag antennas and 8dBm TX power directly from the VCO, a line of sight range of around $375 \mathrm{~m}$ is theoretically possible at $1 \mathrm{GHz}$. 


\section{Conclusions}

A novel transceiver for an RFID backscatter system has been experimentally demonstrated, which uses a simple, but highly sensitive microwave detector. The detector employs a novel injection locked VCO/PLL arrangement. The arrangement has the potential to operate, using phase modulation, over a range of up to $375 \mathrm{~m}$ with 8dBm transmit power due to its enhanced receiver sensitivity.

\section{Acknowledgements}

This work was supported by the UK Engineering and Physical Science Research Council under grant EP/H049606/1.

\section{References}

[1] Xiaorong, G., Sun, J., Wang, C., and Yuan, C.: “CMOS Yields UHF RFID Transmitter” Microwaves and RF, February 2012

[2] Thomas, S.J.; Wheeler, E.; Teizer, J.; Reynolds, M.S., "Quadrature Amplitude Modulated Backscatter in Passive and Semipassive UHF RFID Systems," IEEE Transactions on Microwave Theory and Techniques, vol.60, no.4, pp.1175,1182, April 2012

[3] Cantu, H.I.; Fusco, V.: "Detection sensitivity of self-pulsed self-oscillating millimetre-wave sensor," Electronics Letters , vol.43, no.23, Nov. 82007

[4] Adler, R.: “A Study of Locking Phenomena in Oscillators,” Proc I.R.E., Vol. 34, 1946, pp. 351-357

[5] Kurokawa, K.: "Injection Locking of Microwave Solid-State Oscillators," Proceedings of the IEEE, Vol. 61, NO. 10, October 1973, pp. 1386-1392 

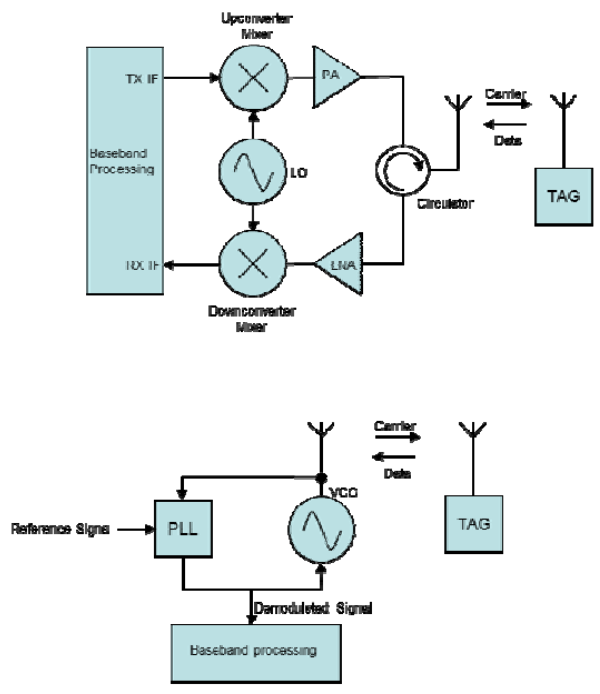

Fig- 1 RFID backscatter systems.

(a) conventional RFID transceiver (b) Injection locked PLL RFID Interrogator

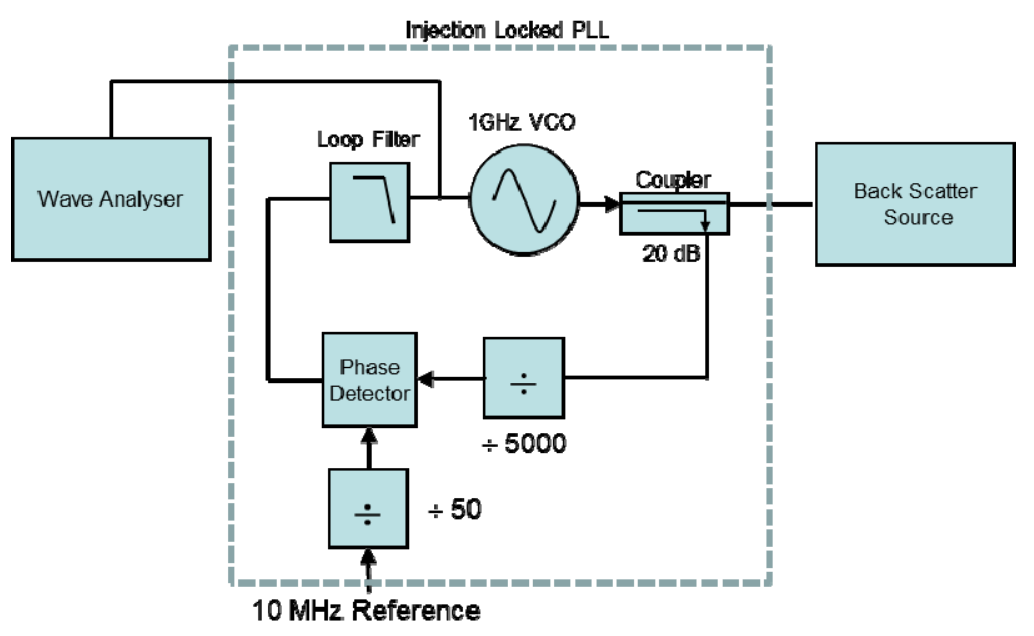

Fig. 2 Experimentalsetup 


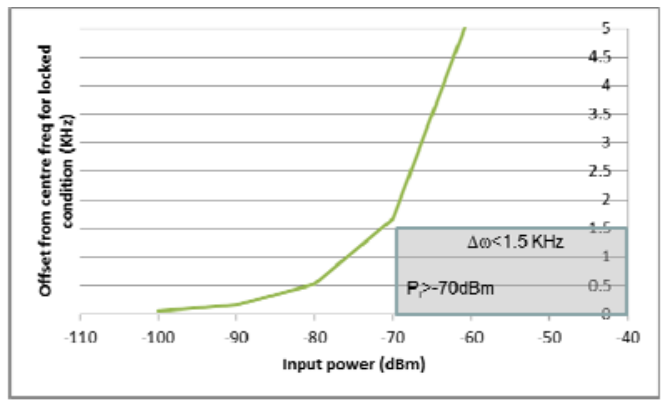

Fig. 3 Colculated frequency offset required to attoin the locked condition of the POS1025 VCO (Qext=75), with various input power levels.

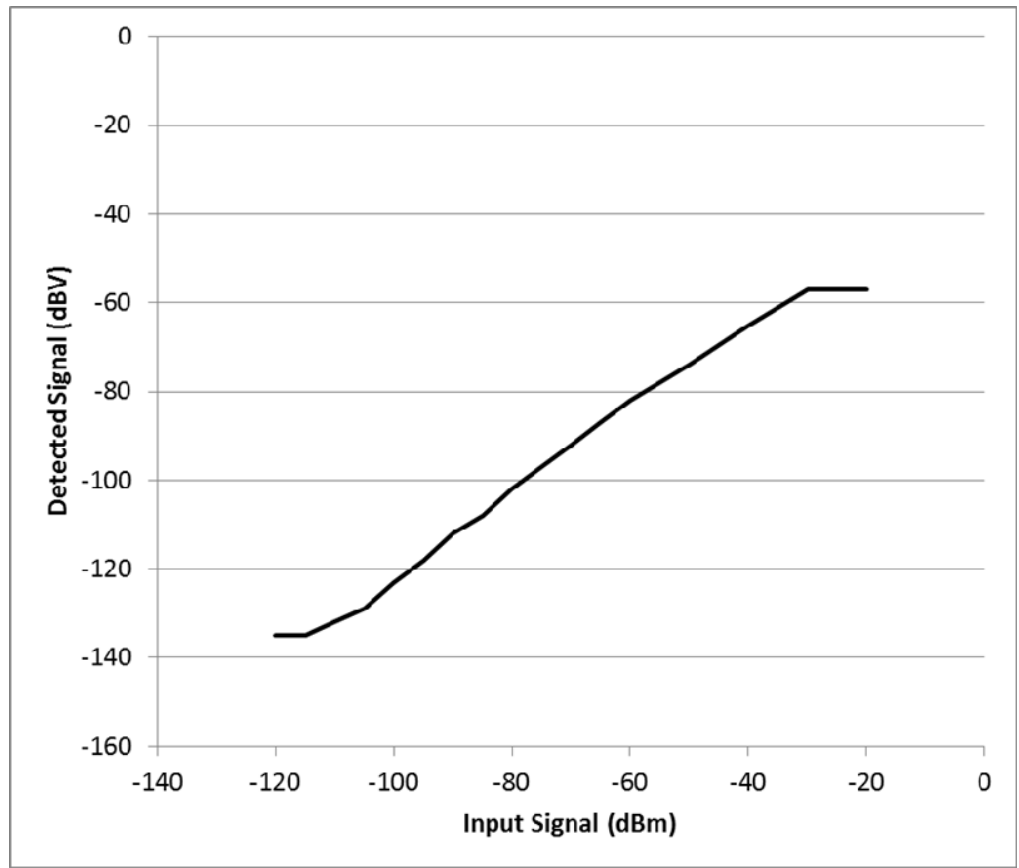

Fig. 4 Sensitivity of injection locked PLL when fed with a 600bps QPSK modulated backscatter signal 